\title{
Effectiveness of orofacial myofunctional therapy in orthodontic patients: A systematic review
}

Márcio Alexandre Homem¹, Raquel Gonçalves Vieira-Andrade², Saulo Gabriel Moreira Falci³,

Maria Letícia Ramos-Jorge ${ }^{4}$, Leandro Silva Marques²

DOI: http://dx.doi.org/10.1590/2176-9451.19.4.094-099.oar

Objective: The aim of the present systematic review was to determine the existence of scientific evidence demonstrating the effectiveness of orofacial myofunctional therapy (OMT) as an adjuvant to orthodontic treatment in individuals with orofacial disorders. A further aim was to assess the methodological quality of the studies included in the review. Methods: An electronic search was performed in eight databases (Medline, BBO, LILACS, Web of Science, EMBASE, BIREME, Cochrane Library and SciELO) for papers published between January 1965 and March 2011, with no language restrictions. Selection of articles and data extraction were performed by two independent researchers. The quality of the selected articles was also assessed. Results: Search strategy resulted in the retrieval of 355 publications, only four of which fulfilled the eligibility criteria and qualified for final analysis. All papers selected had a high risk of bias. Conclusions: The findings of the present systematic review demonstrate the scarcity of consistent studies and scientific evidence supporting the use of OMT in combination with orthodontic treatment to achieve better results in the correction of dentofacial disorders in individuals with orofacial abnormalities.

Keywords: Myofunctional therapy. Orthodontics. Malocclusion.

Objetivo: o objetivo dessa revisão sistemática foi verificar se existem evidências científicas que comprovam a efetividade da TMO como agente coadjuvante do tratamento ortodôntico de indivíduos com distúrbios orofaciais. Além disso, avaliar a qualidade metodológica dos estudos incluídos nessa revisão. Métodos: uma busca eletrônica foi realizada em 8 bases de dados (MEDLINE, BBO, LILACS, Web of Science, EMBASE, BIREME, Cochrane Library e Scielo), sem restrição de idioma. A busca foi realizada com artigos publicados no período compreendido entre janeiro de 1965 a março de 2011. A seleção dos artigos e extração dos dados foi realizada por dois revisores independentes. Avaliação da qualidade dos artigos também foi realizada. Resultados: a estratégia de busca resultou em 355 publicações. Após seleção baseada nos critérios de elegibilidade, quatro artigos foram qualificados para análise final. A todos os artigos incluídos nessa revisão foram atribuídos um alto risco de viés. Conclusões: os resultados do presente estudo demonstram a escassez de estudos consistentes e de evidências científicas que indicam a utilização da TMO em associação ao tratamento ortodôntico com a finalidade de promover melhores resultados na correção de desordens dentofaciais em indivíduos com distúrbios orofaciais.

Palavras-chave: Terapia miofuncional. Ortodontia. Má oclusão.

${ }^{1} \mathrm{MSc}$ in Dentistry, Federal University of the Jequitinhonha and Mucuri Valleys (UFVJM).

${ }^{2} \mathrm{PhD}$ Resident in Dentistry, Federal University of Minas Gerais (UFMG). ${ }^{3}$ Visiting professor, Federal University of the Jequitinhonha and Mucuri Valleys (UFVJM)

${ }^{4}$ Adjunct professor, Department of Dentistry, Federal University of the Jequitinhonha and Mucuri Valleys (UFVJM).

» The authors report no commercial, proprietary or financial interest in the products or companies described in this article.
How to cite this article: Homem MA, Vieira-Andrade RG, Falci SGM, Ramos-Jorge ML, Marques LS. Effectiveness of orofacial myofunctional therapy in orthodontic patients: A systematic review. Dental Press J Orthod. 2014 JulyAug;19(4):94-9. DOI: http://dx.doi.org/10.1590/2176-9451.19.4.094-099.oar

Submitted: October 18, 2012 - Revised and accepted: February 18, 2013

Contact address: Saulo Gabriel Moreira Falci

Rua Tiradentes, 195E - Vila Operária - Diamantina/MG - Brazil

CEP: 39100-000 - E-mail: saulofalci@hotmail.com 


\section{INTRODUCTION}

Orofacial myofunctional therapy (OMT) techniques and principles can be used either alone or in combination with other forms of therapy. ${ }^{1-7}$ In combination with Orthodontics, OMT has been reported to be effective in the treatment of myofunctional disorders. ${ }^{2,5-11}$ According to a number of studies, this combination leads to improvements in myofunctional capacity, allows satisfactory growth and development of the maxilla and assists in the adaptation of dentition to the new occlusal pattern..$^{8,12,13}$ However, a critical literature analysis reveals that most studies on this topic have striking methodological differences, heterogeneous samples and a lack of representativity. ${ }^{3}$ Such limitations have led to divergent results and compromise the quality of evidence, thereby hindering interpretation and clinical application of findings.

OMT generally involves exercising the facial and cervical muscles to improve proprioception, tone and mobility. ${ }^{1,14-18}$ The main objectives are the treatment of disorders of the stomatognathic system, such as orofacial abnormalities, mouth-breathing pattern, lip incompetence, tongue thrust habit, mandibular deviation and improper joint patterns during speech; chewing and swallowing, as well as assistance in the correction of parafunctional oral habits, such as thumb-sucking and bruxism. ${ }^{1,14-24}$ In some cases, OMT may also assist in improving body posture, thereby contributing to overall health. ${ }^{1,14-18}$

Since orofacial disorders increase the degree of difficulty of orthodontic treatment and contribute to the relapse of dentofacial abnormalities, ${ }^{8,9,11}$ OMT may be favorable to orthodontic treatment. Although the literature reports the combination of these therapies to be fundamental to achieve a satisfactory outcome in orthodontic treatment, there have been no systematic reviews carried out to investigate whether this combination is truly capable of achieving better results regarding dentofacial disorders in individuals with orofacial abnormalities.

The aim of the present systematic review was to determine scientific evidence that confirms the effectiveness of OMT as a complement to orthodontic treatment in individuals with orofacial disorders. A further aim was to assess the methodological quality of the studies included in the review.

\section{MATERIAL AND METHODS}

Eligibility criteria were defined by the authors prior to beginning the study. In vivo prospective, longitudinal studies and randomized and/or controlled clinical trials that evaluated the effectiveness of OMT combined with orthodontic treatment in healthy patients with dentofacial deformities were included in the review. Case reports, case series, review articles, opinions and in vitro studies were excluded. No restrictions were made with regard to language.

\section{Type of intervention}

Orthodontic treatment combined with OMT in patients with malocclusions and/or deficiencies in the vertical, sagittal and transverse directions and/or orofacial dyskinesia.

\section{Search strategy}

Searches were performed in the following electronic databases:

" BIREME - Latin American and Caribbean Center of Health Sciences (www.bireme.br).

» LILACS - Latin American and Caribbean Literature on Health Sciences.

" MEDLINE -Medical Literature Analysis and Retrieval System Online.

» Web of Science - Referential database with abstracts in the fields of science, social science, arts and humanities.

" Cochrane Library (http://cochrane.bvsalud.org) database of papers with a high degree of scientific evidence, including systematic reviews, controlled clinical trials, etc.

» $\mathrm{BBO}-$ Brazilian Library of Dentistry.

" SciELO - Online Electronic Scientific Library.

A search was performed for articles published between January 1965 and March 2011, suing the following keywords: "myofunctional therapy", "oral myofunctional therapy", "orofacial myofunctional therapy", "myofunctional therapy effectiveness", "orthodontic treatment and therapy myofunctional", "myofunctional therapy and orthodontics". All these keywords were used in all the aforementioned databases.

\section{Selection criteria and data extraction}

Three selection phases were carried out by two independent researchers, with differences in opinion 
settled by consensus. Initially, all titles were analyzed to eliminate irrelevant publications, review articles, studies involving animals and in vitro studies. All abstracts of the publications selected in the first phase were then analyzed and only those referring to prospective, longitudinal studies and randomized clinical trials were included. The full texts of the articles selected in the second phase were read and eligibility was based on the evaluation of effectiveness of OMT in combination with orthodontic treatment.

A table was constructed with data from all studies and the findings were discussed. The following data were recorded: author, year of publication, study design, study groups, sample, age, methods/measures and assessment of results. A high level of agreement between the two researchers was achieved in this phase.

\section{Quality assessment}

Methodological quality of studies was assessed with a combination of criteria established by $\mathrm{Moose}^{25}$ and

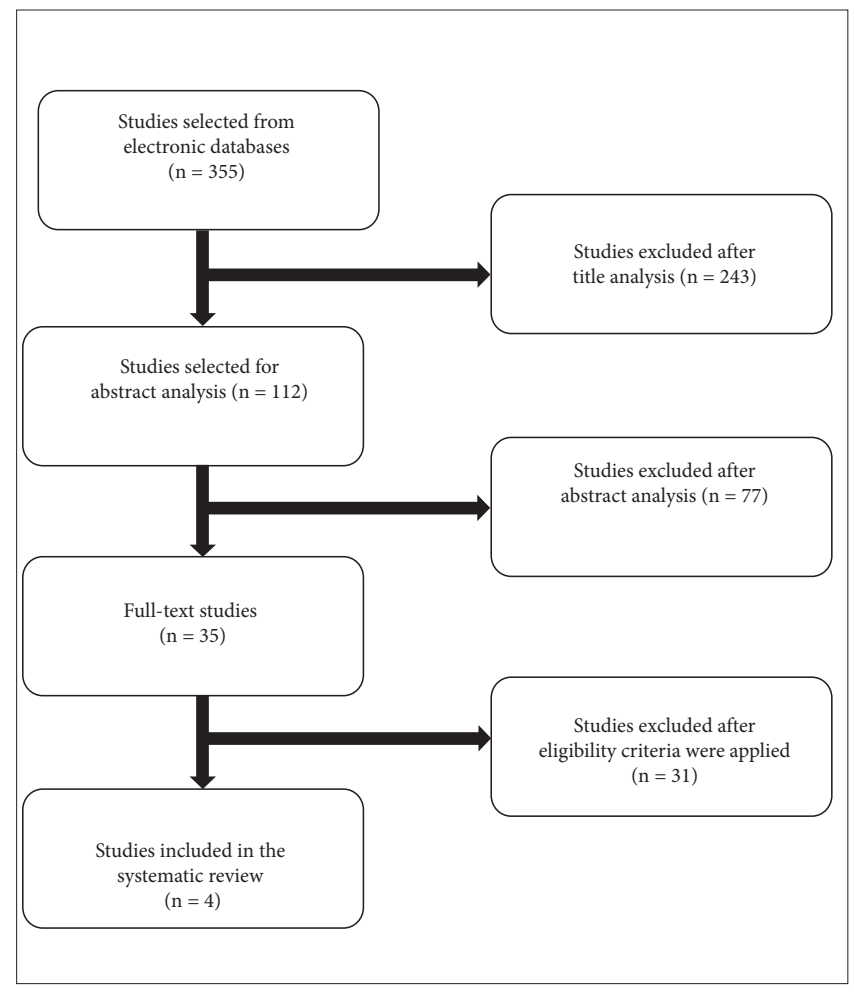

Figure 1 - Flowchart of article selection process.
Prisma. ${ }^{26}$ The risk of bias was considered low when all the following criteria were reported: 1) randomized sample selection; 2) definition of inclusion and exclusion criteria for the sample; 3) declaration of losses during follow-up; 4) use of validated measures; and 5) adequate statistical analysis. When one of these criteria was absent, the risk of bias was considered moderate. When two or more criteria were absent, the risk of bias was considered high.

\section{RESULTS}

Search strategy resulted in 355 articles. Respecting all selection phases based on the eligibility criteria, four articles qualified for final analysis. Figure 1 displays the different steps of the selection process. Table 1 offers a detailed analysis of each article selected for the present systematic review.

\section{Quality of studies}

All articles included in this review had a high risk of bias (Table 2). None of the papers selected presented information on randomized selection of the sample or definition of the inclusion and exclusion criteria.

\section{DISCUSSION}

The present findings should be interpreted with caution, as only four papers met the eligibility criteria established and none exhibited a high degree of scientific evidence. ${ }^{2,5,6,7}$ Thus, while the studies selected indicated the efficacy of OMT in the correction of dentofacial disorders when combined with orthodontic treatment, the scarcity of consistent studies underscores the lack of scientific evidence on the actual effectiveness of OMT as a complement to orthodontic treatment.

From a methodological standpoint, all papers employed adequate statistical tests for data analysis., ${ }^{2,5,6,7}$ However, the considerable diversity of tests, together with the low number of studies included in the present review, impede carrying out a meta-analysis. Comparisons with other studies are also limited due to differences in study design, sample selection and sample size.

Two studies included in the present systematic review $^{5,7}$ were carried out to determine the effectiveness of OMT alone (control group) and in combination with 
Table 1 - Characteristics of studies selected.

\begin{tabular}{|c|c|c|c|c|c|c|}
\hline $\begin{array}{l}\text { Author } \\
\text { (year) }\end{array}$ & $\begin{array}{l}\text { Study } \\
\text { design }\end{array}$ & Study groups & Sample & Age & $\begin{array}{l}\text { Methods/ } \\
\text { Measures }\end{array}$ & Assessment of results \\
\hline $\begin{array}{c}\text { Trawitzki } \\
\text { et al }{ }^{6}\end{array}$ & LS & $\begin{array}{l}\text { Experimental group: } \\
\text { *P1 (before surgery): patients with } \\
\text { Class III malocclusion } \\
\text { *P3 (same patients } 3 \text { years and } 3 \\
\text { years and } 8 \text { months after surgery): } \\
\text { Finalization of orthodontic } \\
\text { treatment and OMT } \\
\text { Control group: } \\
\text { Individuals without morphological } \\
\text { facial abnormalities }\end{array}$ & $\begin{array}{l}13 \\
15\end{array}$ & $21 / 42$ & $\begin{array}{l}\text { Ultrasound } \\
\text { of masseter } \\
\text { muscle at rest } \\
\text { and occlusion } \\
\text { Linear } \\
\text { regression test }\end{array}$ & $\begin{array}{l}\text { Significantly greater }(P<0.01) \text { masseter muscle } \\
\text { thickness }(\mathrm{cm}) \text { in } P 3 \text { group }\end{array}$ \\
\hline $\begin{array}{l}\text { Smithpeter } \\
\text { and Covell } \\
\mathrm{Jr}^{2}\end{array}$ & LS & $\begin{array}{l}\text { Patients with anterior open bite } \\
\text { Experimental cohort group: } \\
\text { Individuals who received } \\
\text { orthodontic treatment or } \\
\text { retreatment and OMT } \\
\text { Control cohort group: Individuals } \\
\text { with history of orthodontic } \\
\text { treatment with relapse of open bite }\end{array}$ & $\begin{array}{l}27 \\
49\end{array}$ & $8 / 41$ & $\begin{array}{l}\text { T-test } \\
\text { Analysis of } \\
\text { covariance } \\
\text { Linear } \\
\text { regression } \\
\text { Correlation } \\
\text { coefficient }\end{array}$ & $\begin{array}{l}\text { - Relapse was } 0.5 \mathrm{~mm} \text { in experimental group and } \\
3.4 \mathrm{~mm} \text { in control group (significant difference) } \\
\text { - OMT combined with orthodontic treatment } \\
\text { was more effective in closure and maintenance } \\
\text { of closure of anterior open bite in comparison to } \\
\text { orthodontic treatment alone }\end{array}$ \\
\hline Daglio et $\mathrm{al}^{5}$ & CCT, LS & $\begin{array}{l}\text { Patients with malocclusions, } \\
\text { deficiencies in vertical, sagittal and } \\
\text { transverse dimensions and orofacial } \\
\text { dyskinesis } \\
\text { Control group (A): } \\
\text { Treated with OMT alone } \\
\text { Experimental group (B): treated with } \\
\text { combined OMT and orthodontic } \\
\text { appliance }\end{array}$ & $\begin{array}{l}13 \\
15\end{array}$ & $8 / 17$ & $\begin{array}{c}\text { Statistical } \\
\text { homogeneity } \\
\text { Payne test } \\
\text { Frequency } \\
\text { analysis }\end{array}$ & $\begin{array}{l}\text { - Group A: Reduction in overjet from } 3.5 \text { to } 2.6 \mathrm{~mm} \text {; } \\
\text { angle of base of mandible reduced from } 30^{\circ} \\
\text { to } 28.31^{\circ} \text {; ANB angle reduced from } 4.4^{\circ} \text { to } 2.7^{\circ} \text {; } \\
\text { statistically significant changes; better results with } \\
\text { correction of overbite, which was normalized from a } \\
\text { mean of }-2.46 \text { to } 3.06 \mathrm{~mm} \\
\text { - Group B: Reduction in overjet from } 6.6 \text { to } 2.6 \mathrm{~mm} \text {; } \\
\text { overbite improved from mean of }-1.2 \text { to }+2.9 \mathrm{~mm} \text {; } \\
\text { angle of base of mandible reduced from } 31.2^{\circ} \text { to } \\
27.8^{\circ} \text {; ANB angle reduced from } 7.3^{\circ} \text { to } 3.7^{\circ}\end{array}$ \\
\hline Daglio et $\mathrm{al}^{7}$ & CCT, LS & $\begin{array}{l}\text { Patients with orofacial dyskinensia } \\
\text { and anterior open bite } \\
\text { Experimental group: } \\
\text { OMT + orthodontic treatment } \\
\text { Control group: } \\
\text { OMT alone }\end{array}$ & 75 & $6 / 22$ & $\begin{array}{l}\text { Payne test } \\
\text { Homogeneity } \\
\text { test } \\
\text { Cephalometric } \\
\text { analysis } \\
\text { Correlation } \\
\text { analysis } \\
\text { Frequency } \\
\text { analysis }\end{array}$ & $\begin{array}{l}\text { Combination of OMT and orthodontic treatment was } \\
\text { more successful in correction of resting lip posture } \\
\text { than OMT alone }\end{array}$ \\
\hline
\end{tabular}

LS - Longitudinal Study, CCT - Controlled Clinical Trial.

Table 2 - Quality assessment of studies selected.

\begin{tabular}{|c|c|c|c|c|}
\hline Quality criteria & Trawitzki et al ${ }^{6}$ & Smithpeter and Covell Jr² & Daglio et al ${ }^{5}$ & Daglio et al ${ }^{7}$ \\
\hline Randomized sample selection & No & No & No & No \\
\hline $\begin{array}{c}\text { Definition of inclusion and } \\
\text { exclusion criteria }\end{array}$ & No & No & No & No \\
\hline Declaration of losses during follow-up & No & Yes & No & No \\
\hline Use of validated measures & Yes & Yes & No & No \\
\hline Adequate statistical analysis & Yes & Yes & Yes & Yes \\
\hline Estimated potential risk of bias & High & High & High & High \\
\hline
\end{tabular}


orthodontic treatment (experimental group). In one of these studies, ${ }^{5}$ the authors assessed patients with malocclusions, deficiencies in the vertical, sagittal and transverse dimensions and orofacial dyskinesia. Based on the findings, the authors report that patients with dyskinesia and malocclusions can be treated with both forms of therapy. In the other study involving only patients with orofacial dyskinesis and anterior open bite, ${ }^{7}$ the researchers found that the combination of OMT and orthodontic treatment was more successful in correcting lip incompetence than OMT alone. While their findings favor a combined therapeutic approach, the authors report that the decision regarding the use of OMT alone or in combination with orthodontic treatment is not conclusive and better planned studies are needed. Moreover, both studies have a high risk of bias and a substantial limitation, namely, that only one group was submitted to orthodontic treatment. Thus, the difference between groups is mainly related to the administration of orthodontic treatment.

Another article analyzed herein ${ }^{2}$ assessed the effectiveness of OMT as a complement to maintaining closure of anterior open bite following orthodontic treatment or retreatment. The main conclusion was that the relapse of open bite in the experimental group treated with both orthodontics and OMT $(0.48 \pm 0.8 \mathrm{~mm})$ was significantly less than that in the control group treated with orthodontics alone $(3.38 \pm 1.3 \mathrm{~mm})(\mathrm{P}<0.0001)$. Therefore, the authors indicate the combination of these two forms of therapy for anterior open bite and stress the importance of documenting the oral and functional habits of each patient, along with the traditional orthodontic records, in any study aimed at assessing the efficacy of treatment for open bite. Such an investigation would allow one to determine what kind of patients would benefit from the combination of OMT and orthodontic treatment and what kind of patients would have a good prognosis with the use of orthodontic appliances alone.

The most recent paper selected for this review ${ }^{6}$ assessed the effect of integrated treatment combining orthodontics, orthognathic surgery and OMT on the thickness of the masseter muscles in patients with Class III deformity. Although the study included orthognathic surgery as part of orthodontic treatment, the authors found that combined treatment with OMT and orthodontics led to an improvement in masseter muscle thickness in patients following orthognathic surgery in comparison to baseline and the control group. However, these findings should be interpreted with caution considering the high risk of bias as well as the fact that the difference between groups may have been related to the surgery itself, which was likely the main reason for the improvement in muscle thickness.

To reiterate, while the studies selected for the present systematic review indicate effectiveness of OMT in correcting dentofacial deformities when combined with orthodontic treatment, a number of limitations are found, especially with regard to the number and quality of the studies analyzed. Moreover, the papers investigated specific occlusal problems, such as anterior open bite, orofacial dyskinesia and masseter muscle thickness, which make the results quite particular to specific conditions. As one third of the population requires orthodontic treatment, ${ }^{27}$ further studies with more rigorous methods, such as randomized, controlled clinical trials, should be carried out to determine the actual effectiveness of OMT as a complement to orthodontic treatment.

\section{CONCLUSION}

The findings of the present systematic review demonstrate a scarcity of consistent studies and scientific evidence supporting the use of OMT in combination with orthodontic treatment to achieve better results in the correction of dentofacial disorders in individuals with orofacial abnormalities. Studies with a high standard of quality and better study design are needed to establish strong scientific evidence that supports the indication of this form of combined therapy. 


\section{REFERENCES}

1. Benkert KK. The effectiveness of orofacial myofunctional therapy in improving dental occlusion. Int J Orofacial Myology. 1997:23:35-46.

2. Smithpeter J, Covell D Jr. Relapse of anterior open bites treated with orthodontic appliances with and without orofacial myofunctional therapy. Am J Orthod Dentofacial Orthop. 2010;137(5):605-14.

3. Takahashi O, Iwasawa T, Takahashi M. Integrating orthodontics and oral myofunctional therapy for patients with oral myofunctional disorders. Int J Orofacial Myology. 1995;21:66-72.

4. Yamaguchi $\mathrm{H}$, Sebata M. Changes in oral functions and posture at rest following surgical orthodontic treatment and myofunctional therapy. Evaluation by means of video recording. Int J Orofacial Myology. 1995:21:29-32.

5. Daglio S, Schwitzer R, Wüthrich J. Orthodontic changes in oral dyskinesia and maloclusion under the influence of myofunctional therapy. Int J Ororfacial Myology. 1993:19:15-24.

6. Trawitzki LV, Dantas RO, Elias-Júnior J, Mello-Filho FV. Masseter muscle thickness three years after surgical correction of class III dentofacial deformity. Arch Oral Biol. 2011:56(8):799-803.

7. Daglio SD, Schwitzer R, Wüthrich J, Kallivroussis G. Treating orofacial dyskinesia with functional physiotherapy in the case of frontal open bite. Int J Ororfacial Myology. 1993:19:11-4.

8. Klocke A, Korbmacher H, Kahl-Nieke B. Influence of orthodontic appliances on myofunctional therapy. J Orofac Orthop. 2000;61(6):414-20.

9. Ohono T, Yogosawa F, Nakamura K. An approach to open bite cases with tongue thrusting habits with reference to habit appliances and myofunctional therapy as viewed from an orthodontic standpoint. Int J Orofacial Myology. $1982 ; 7: 3-10$

10. Freitas KMS, Freitas MR, Janson G, Henriques JFC, Pinzan A. Avaliação pelo indice PAR dos resultados do tratamento ortodôntico da má oclusão de Classe tratada com extrações. Rev Dental Press Ortop Facial. 2009;13(2):94-104

11. Toronto AS. Long-term effectiveness of oral myotherapy. Int J Oral Myol. 1975;1(4):132-6.

12. Tartaglia GM, Grandi G, Mian F, Sforza C, Ferrario VF. Non-invasive 3D facial analysis and surface electromyography during functional pre-orthodontic therapy: a preliminary report. J Appl Oral Sci. 2009;17(5):487-94.

13. Yagci A, Uysal T, Kara S, OkkeYes S. The effects of myofunctional appliance treatment on the perioral and masticatory muscles in class II, division I patients. World J Orthod. 2010;11(2):117-22.

14. Das UM, Beena JP. Effectiveness of circumoral muscle exercises in the developing dentofacial morphology in adenotonsillectomized children: an ultrasonographic evaluation. J Indian Soc Pedod Prev Dent. 2009;27(2):94-103.
15. Felício CM, Melchior MO, Ferreira CL, Silva MA. Otologic symptoms of temporomandibular disorder and effect of orofacial myofunctional therapy. Cranio. 2008;26(2):118-25.

16. Ruscello DM. Nonspeech oral motor treatment issues related to children with developmental speech sound disorders. Lang Speech Hear Serv Sch. 2008;39(3):380-91.

17. Kumar TV, Kuriakose S. Ultrasonographic evaluation of effectiveness of circumoral muscle exercises in adenotonsillectomized children. J Clin Pediatr Dent. 2004:29(1):49-55.

18. Ray J. Orofacial myofunctional therapy in dysarthria: a study on speech intelligibility. Int J Ororfacial Myology. 2002;28:39-48.

19. Mason, RM. A retrospective and prospective view of orofacial mycology. Int J Orofacial Myology. 2008;34:5-14.

20. Degan W, Puppin-Rontani RM. Removal of sucking habits and myofunctional therapy: establishing swallowing and tongue rest position. Pro Fono. 2005;17(3):375-82.

21. Korbmacher HM, Schwan M, Berndsen S, Berndsen S, Bull J, Kahl-Nieke B. Evaluation of a new concept of myofunctional therapy in children. Int J Orofacial Myology. 2004;30:39-52.

22. Magnusson T, Syrén M. Therapeutic jaw exercises and interocclusal appliance therapy. A comparison between two common treatments of temporomandibular disorders. Swed Dent J. 1999:23(1):27-37.

23. Tallgren A, Christiansen RL, Ash M Jr, Miller RL. Effects of a myofunctional appliance on orofacial muscle activity and structures. Angle Orthod. 1998;68(3):249-58.

24. Umberger FG, Johnston RG. The efficacy of oral myofunctional and coarticulation therapy. Int J Orofacial Myology. 1997:23:3-9.

25. Stroup DF, Berlin JA, Morton SC, Olkin I, Williamson GD, Rennie D, et al. Metaanalysis of observational studies in epidemiology: a proposal for reporting. Meta-analysisof Observational Studies in Epidemiology (MOOSE) group. J Am Med Assoc. 2000;283(15):2008-12.

26. Liberati A, Altman DG, Tetzlaff J, Mulrow C, Gotzsche PC, loannidis JPA, et al. The PRISMA statment for reporting systematic reviews and meta-analysis os studies that evaluate health care interventions: explanation and elaboration J Clin Epidemiol. 2009;62(10):e1-34.

27. Dias PF, Gleiser R. Orthodontic treatment need in a group of 9-12-year-old Brazilian schoolchildren. Braz Oral Res. 2009;23(2):182-9. 